\title{
Thermal stability of the elastomeric anti-trauma pad
}

\author{
Karolina Olszewska $^{1^{*}}$, Dorota Zielinska ${ }^{1}$, Marcin H. Struszczyk ${ }^{1}$, Łukasz Wierzbicki ${ }^{2}$, \\ Marcin K. Leonowicz ${ }^{2}$ \\ ${ }^{1}$ Institute of Security Technologies "MORATEX", M. Sklodowskiej-Curie Str. 3, 90-505 Lodz, Poland \\ ${ }^{2}$ Warsaw University of Technology, Faculty of Materials Science and Engineering, Wołoska 141, 02-507 Warsaw, Poland \\ *corresponding author: e-mail: kolszewska@moratex.eu
}

\begin{abstract}
The elastomeric anti-trauma pad (EA-TP) based on shear thickening fluid (STF) has been developed. Dynamic oscillatory shear experiment was conducted at constant strain amplitude of 5\%. STF composed of $25 \%$ of volume fraction of $7 \mathrm{~nm}$ Fumed Silica, dispersed in polypropylene glycol with molar mass $400 \mathrm{gmol}^{-1}$ shows elastic properties in entire investigated range of the frequency. Ballistic tests of EA-TP with $7.62 \mathrm{~mm}$ x $39 \mathrm{~mm}$ PS bullets were performed according to the PN-V-87000:2011 standard. The studies revealed about $60 \%$ reduction of the average backface signature depth (BSD) for the EA-TP, when compared to the nowadays commonly used soft insert. The ATR-FTIR analysis confirmed slight impact of the elevated temperature and air (oxygen) on the chemical degradation of the EA-TP surface. The UV-VIS spectroscopy has allowed to notice colour deviation of the aged samples towards green and yellow, as well as lack of dye resistance to accelerated aging process. Thermographic analysis has shown no visible changes of the EA-TP surface and sub-surface during accelerated aging process. The aforementioned small changes on the surface of EA-TP did not affect the ballistic properties of composite armour. EA-TP insert maintains ballistic properties after accelerated aging process which was simulating the period of 6 years according to ASTM F1980 - 07:2002 standard.
\end{abstract}

Keywords: anti-trauma pad, shear thickening fluid, accelerated aging.

\section{INTRODUCTION}

Stability of the properties is one of the most important requirements of the products designed to protect human health and life. According to the PN-V-87000:2011 Standard ${ }^{1}$ the ballistic vests inserts should maintain their durability for a period of 6 years since the date of manufacture. Nevertheless in the above-mentioned document there is no information about the method of determining the usability period. The NIJ Standard- $0101.06^{2}$ defines methodology of tests which determine the influence of environmental factors on the aging processes and expiration date for bullet- and fragment-proof vests. The specified conditions of accelerated aging include, i.a.: temperature of $65^{\circ} \mathrm{C}$, humidity of $80 \%$, time of 10 days. What is more, ballistic properties especially the V50 parameter (the velocity at which the projectile is expected to perforate an armor specimen $50 \%$ of the time) of a sample which was exposed to the accelerated aging process, should be compared to the non-aged sample.

In recent years, the studies on ballistic products resistance to the influence of environmental factors were undertaken. For instance, a series of studies on that subject was carried-out by DSM (DSM is a global science-based company active in health, nutrition and materials). The composite panels made of polyethylene fibrous materials: Dyneema ${ }^{\circledR} \mathrm{HB} 26$ and Dyneema ${ }^{\circledR} \mathrm{HB}$ 2 were subjected to a natural aging process of 4 years. The same ballistic materials were exposed for the accelerated aging process during 20 weeks at the temperature of $65^{\circ} \mathrm{C}$ and $90^{\circ} \mathrm{C}^{3}$. The ballistic properties determined by the V50 parameter exhibited 1-2\% reduction of V50 values when compared to the non-aged samples.

The accelerated aging studies performed by Chabba et al. ${ }^{4}$ concerned Dyneema ${ }^{\circledR}$ SK 76 yarns and Dyneema ${ }^{\circledR}$ UD polyethylene material. According to Chabba, oxidation is the most important process for polyolefins that contributes towards aging. The studies lasted 8 weeks and was performed at the temperature of $65^{\circ} \mathrm{C}$ and relative humidity of $80 \%$ (which corresponds to 5 years of natural aging at the temperature of $35^{\circ} \mathrm{C}$, according to Arrhenius plots for Dyneema ${ }^{\circledR}$ SK76 and Dyneema ${ }^{\circledR}$ SB). The results of research proved, that after such a period of time, the materials keep their mechanical properties, and their ballistic resistance (determined by the ballistic limit V50 according to the $9 \mathrm{~mm}$ FMJ bullet Standard ${ }^{5}$ ).

The durability of 25-layers packets of Dyneema ${ }^{\circledR}$ UD SB 21, which were conditioned at the temperature of $75^{\circ} \mathrm{C}$ and humidity of $80 \%$ during various periods of time (1, 2, 4 and 8 weeks) was studied in ${ }^{6}$. Both the aged packets and non-aged ones were assessed for changes of ballistic properties determined by the parameter of ballistic resistance $\mathrm{V} 50^{7}$ with the use of $9 \mathrm{~mm}$ FMJ bullet. After 1 week of aging the V50 parameter decreased by approx. $2.5 \%$. Nevertheless after 2 and 4 weeks a small increase in V50 was observed. The authors performed also tests of V50 (with the use of $7.62 \times 39 \mathrm{~mm}$ AK47 MSC bullets) of panels (made of 73 layers of Dyneema ${ }^{\circledR} \mathrm{HB}$ 2, 80 layers of Dyneema ${ }^{\circledR}$ HB 26, 68 layers of Dyneema ${ }^{\circledR}$ HB 50) conditioned at the temperature of $65^{\circ} \mathrm{C}$ and $90^{\circ} \mathrm{C}$ and humidity of $80 \%$ during $2,4,8,12,16$ and 20 weeks. Also in this case, no significant changes in ballistic resistance were observed. The maximum decrease of V50 was found in the panel made of 73 layers of Dyneema ${ }^{\circledR}$ HB 26 after 8 and 16 weeks of conditioning at $90^{\circ} \mathrm{C}$.

The studies on ballistic properties of vests, inserts and helmets made of Dyneema ${ }^{\circledR}$ UD (SB 2 and SB 21) used by military units have been discussed in $^{7}$. The vests and inserts originated from: 1999, 2000-2002 and 2004-2006, while the helmets from 2002 and 2006. The products were visually examined, and consequently tested according to the relevant standards. Assessments of the V50 parameter, the penetration of the sample and the average backface signature depth were studied. 
The V50 test proved, that Dyneema ${ }^{\circledR}$ UD SB keeps the ballistic resistance. Based on those results, the authors proved, that the obtained ballistic resistance of natural aged protectors made of Dyneema ${ }^{\circledR}$ UD SB, fits to the expectations made on the basis of accelerated aging.

The Institute of Security Technologies "MORATEX" has also carried out research on the influence of the aging process (in natural and accelerated conditions) on ballistic properties of UHMWPE (Ultra-High-MolecularWeight Polyethylene). In the study ${ }^{8}$ authors have assessed the progress of the aging process of selected samples by determining changes in their structure, mechanical and ballistic properties. According to the PN-V-87000:1999 Standard $^{9}$ it was proved that the bullet-proof vests of third class after 5 years of usage as well as the inserts made of Dyneema ${ }^{\circledR}$ UD SB 21 exposed to accelerated aging in a laboratory, retain the protective properties as declared. Nevertheless the influence of temperature and humidity caused a remarkable reduction of the mechanical and ballistic properties of tested samples. The effect increased during prolonged exposure.

This study assumed, that replacing a commonly used soft insert from the typical ballistic armour with the newlydeveloped elastomeric pad (EA-TP) shall contribute in decreasing an average backface signature depth, and as a result, it would allow for reduction of the injury risk of a user.

The aim of the presented study was to verify the ballistic properties of the new anti-trauma products, as well as the stability of the ballistic properties over specific amount of time which was simulated in accelerate aging chamber.

\section{MATERIAL AND METHODS}

\section{Materials}

Initial materials. Additive silicone (ZA 22 MOULD, Zhermack ${ }^{\circledR} /$ Poland) and microspheres (461 DET 40 d25 Expancel ${ }^{\circledR}$, Akzo Nobel/The Netherlands) were used in this study. The shear thickening fluid (STF) was composed of $25 \%$ of volume fraction of $7 \mathrm{~nm}$ fumed silica (FS7, Sigma Aldrich/USA), dispersed in polypropylene glycol (PPG400) with molar mass $400 \mathrm{gmol}^{-1}$ (Sigma Aldrich/USA), by Warsaw University of Technology (Faculty of Materials Science and Engineering).

The composite ballistic panels (82 UHMWPE layers of the Dyneema ${ }^{\circledR} \mathrm{HB} 50, \mathrm{DSM} /$ The Netherlands) and soft inserts (46 UHMWPE layers of the Dyneema ${ }^{\circledR} \mathrm{HB}$ 21, DSM/The Netherlands) were designed on base of ${ }^{\mathbf{1 0}}$.

Designing of the elastomeric anti-trauma pads (EA-TP). Additive silicone and microspheres in an amount of $1.2 \%$ vol. (filled with an inert gas) were mixed. Then the obtained mass was put into the designed molds, as shown in Figure $1 \mathrm{~A}$ and $\mathrm{B}$ and left to cross-link for 5 hours at the room temperature $\left(23^{\circ} \mathrm{C} \pm 3^{\circ} \mathrm{C}\right)$. Elastomeric mould no. 1 was filled with STF and covered with mould no. 2 and again left for proper cross-link for another 5 hours at $23^{\circ} \mathrm{C} \pm 3^{\circ} \mathrm{C}$. After this time a durable connection of the two parts of the elastomeric pad was obtained. The Figure 2 shows a cross-section of the elastomeric pad.
A)

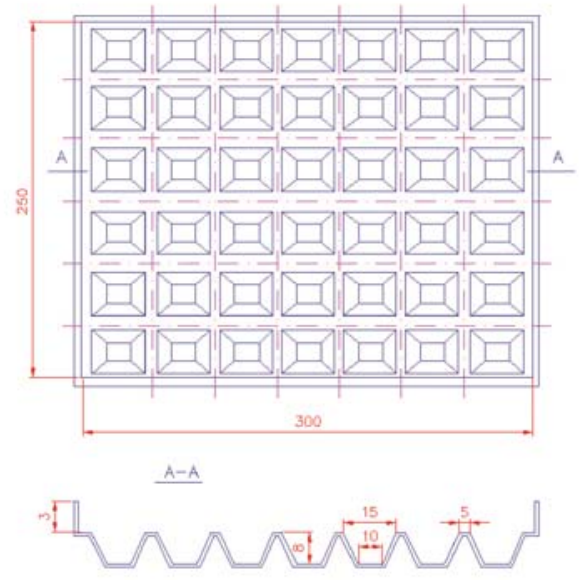

B)
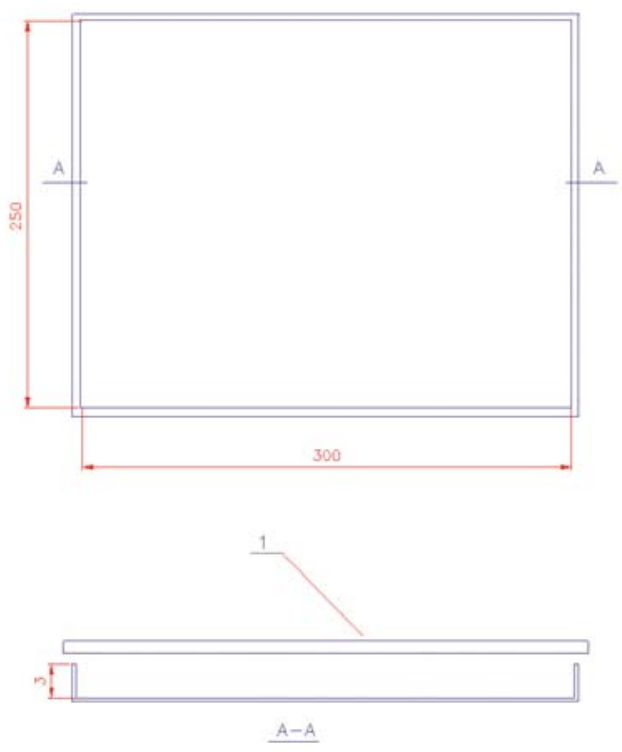

Figure 1. 1 (A) Form no. 1 (B) Form no. 2 for designing EA-TP

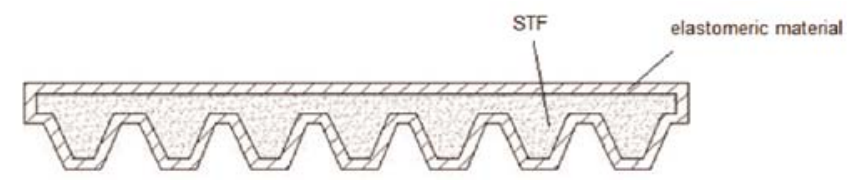

Figure 2. Part of the EA-TP - cross-section

\section{METHODS}

\section{Rheological studies}

Rheological studies were performed using ARES-LS2 TA Instruments ${ }^{\circledR}$ rheometer (New Castle, DE/USA) equipped with two parallel plates (diameter $25 \mathrm{~mm}$ ), with a gap between them of $0.3 \mathrm{~mm}$. All measurements were taken at room temperature.

\section{Acceleration aging}

The accelerated aging tests of EA-TP have been performed in the thermostatic chamber (SUP-65 WG, WAMED/Poland) according to the guidelines based on the ASTM F1980-07:2002 standard $^{11}$ and the outcomes available in literature ${ }^{6}$. The specified conditions of accelerated aging was set up: temperature $70.0^{\circ} \mathrm{C} \pm 0.5^{\circ} \mathrm{C}$ (selected from the document ${ }^{\mathbf{1 2}}$ ) and three time periods: 28,56 or 84 days (which simulated the three time periods 
of natural aging: 2, 4 or 6 years according to ASTM F1980-07:2002 standard).

\section{Ballistic tests}

The ballistic armours for ballistic tests were made with the use of composite panels with EA-TP. The tested system is shown in the Figure 3. As a reference, the system made of the same composite panel with commonly used soft ballistic insert was applied. Ballistic tests of EA-TP were performed on the samples before and after accelerated aging according to the PBB-17/ITB:2011 Standard ${ }^{\mathbf{1 3}}$, which is compliant with NIJ Standard-0101.06 ${ }^{2}$. The 7.62 mm x 39 mm PS (mass $7.9 \mathrm{~g} \pm 0.1 \mathrm{~g}$ ) bullets were used with an impact velocity of $720 \pm 15 \mathrm{~ms}^{-1}$ which refers to $\mathrm{K} 3 \mathrm{~A}$ class. During the tests the following parameters were measured:

- average bullets velocity,

- average backface signature depth, BSD,

- perforation.

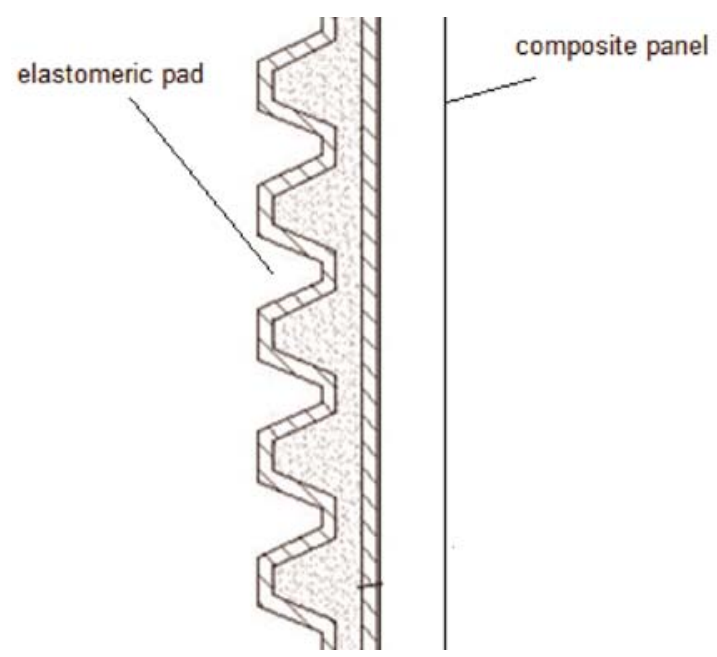

Figure 3. Scheme of the tested system EBS - ballistic armour consisting in elastomeric pad (EA-TP; at side of the body) and ballistic composite panel

\section{Spectroscopy analysis}

The UV-VIS spectroscopy was performed using an UV-VIS-NIR (Model V-670) spectrophotometer (Jasco/USA) which was equipped with ILN-725 integrating sphere. Spectral analysis has been carried out with the specific parameters: UV-VIS spectral width: $10 \mathrm{~nm}$, NIR spectral width: $40 \mathrm{~nm}$, wavelength range: $35-800 \mathrm{~nm}$, scanning speed: $400 \mathrm{~nm} / \mathrm{min}$, number of measurement cycles: 1 .

The $\mathrm{L}^{*}$ and $\mathrm{a}^{*}$ and $\mathrm{b}^{*}$ coordinates have been calculated with the Colour Analysis software with the pre-set parameters according to the JIS Z8701-1999 standard.

\section{Thermographic analysis}

Thermographic analysis of the EA-TP in the infra-red band were performed according to the PBB-25/ITB:2012 Standard ${ }^{14}$, with the use of high resolution FLIR A310 (FLIR ${ }^{\circledR} /$ USA) camera. The thermal images created during cooling as well as the changes of temperature of the EA-TP were recorded after each of three ageing cycles.

Based on the equation:

$\Delta \mathrm{T}=\Delta \mathrm{T}_{0} \cdot e^{-k t}$

where:

$\mathrm{T}$ - temperature of sample $\left({ }^{\circ} \mathrm{C}\right)$,

$\mathrm{T}_{\mathrm{o}}$ - temperature of environment $\left({ }^{\circ} \mathrm{C}\right)$, $\mathrm{k}$ - cooling rate constant,

$\mathrm{t}$ - time ( $\mathrm{s}$ )

the cooling rate constants $(\mathrm{k})$ were calculated. For that purpose the equation (1) has been logarithmised, to get the following linear correlation:

$\ln \Delta \mathrm{T}=-k t+\ln \Delta \mathrm{T}_{0}$

From the curve of function $\ln \Delta \mathrm{T}=f(t)$ the cooling rate constant (k) was read, as the slope of the line:

$a=\operatorname{tg} \alpha=-k$

Values of the constants $(\mathrm{k})$ were calculated for the samples after each of the three ageing cycles.

\section{ATR-FTIR study}

The Attenuated total reflection Fourier transform infrared (ATR-FTIR) spectroscopy with the use of high refractive index crystal ( $\mathrm{ZnSe}$ ) allowed for providing meaningful information about aging process of tested samples. Nicolet (Model iS10) spectrometer (Thermo Scientific/USA) was used and the spectra have been measured with the use of ATR (Attenuated Total Reflection) technique. Parameters of the measurement: scope of wavelength: $400 \mathrm{~cm}^{-1}-4000 \mathrm{~cm}^{-1}$, at a resolution of: $4 \mathrm{~cm}^{-1}$, number of scanning passes: 16 .

\section{RESULTS AND DISCUSSION}

\section{Rheological results}

Steady rheological behavior. Figure 4 shows the dependence of the viscosity on the shear rate for the suspension composed with $25 \%$ of volume fraction fumed silica dispersed in polypropylene glycol with molar mass $400 \mathrm{~g} / \mathrm{mol}$ (PPG400). One can clearly see that the viscosity of the fluid is increasing with growing shear rate. It means that the fluid have shear thickening properties. Critical shear rate for this suspension is about $6\left[\mathrm{~s}^{-1}\right]$, and the maximum obtained viscosity is about 1150 [Pa s].

Dynamic frequency sweep rheological behavior. Elastic modulus (G') and viscous modulus (G') as a function of sweep frequency for $25 \%$ vol. fraction of FS dispersed in PPG400 are plotted in Figure 4. The experiment was performed from low to high sweep frequency at constant strain of $5 \%$. It can be observed from Figure 5 that elastic modulus G' exceeds viscous modulus $G$ " in the entire frequency range. It means that the system is elastic in the entire frequency range.

$25 \%$ vol. Fraction of FS7 dispersed in PPG400

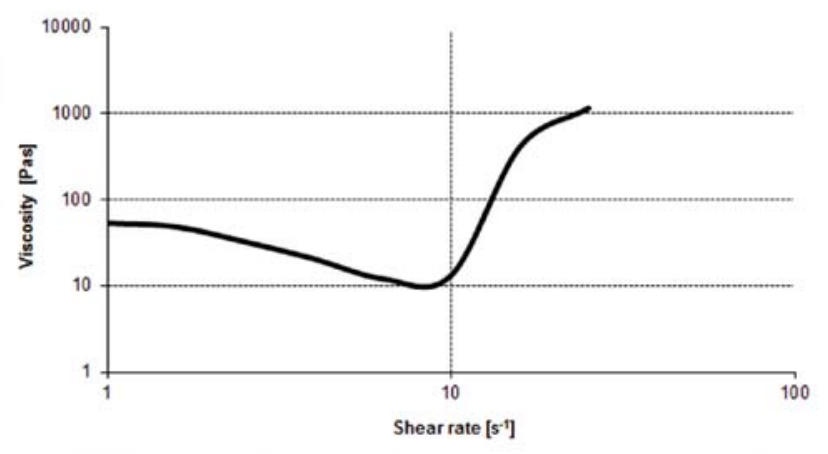

Figure 4. Apparent viscosity as a function of shear rate of $25 \%$ vol. fraction of FS dispersed in PPG400 


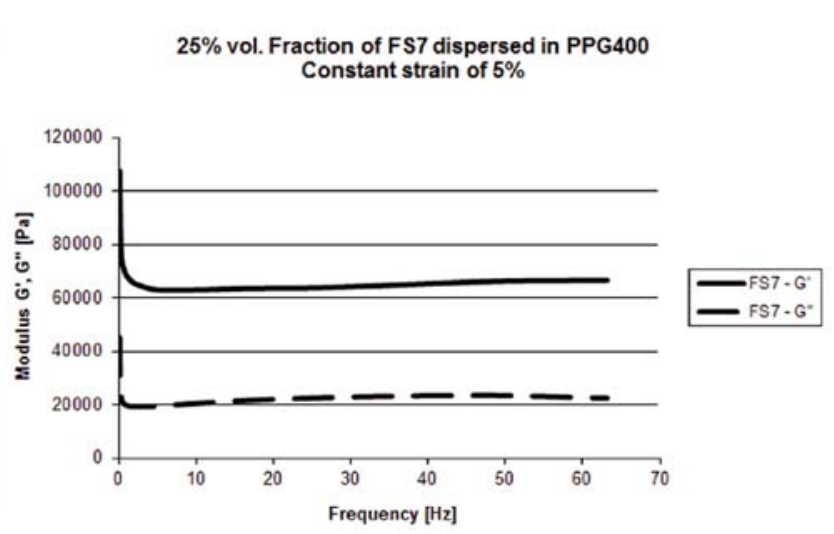

Figure 5. Moduli (G' and G') of 25\% vol. fraction of FS suspension in PPG400 as function of sweep frequency at constant strain of $5 \%$

\section{Ballistic test results}

In order to compare the protective capabilities of the ballistic inserts, two systems were examined. Each of them included a profiled composite panel, consisting of 82 layers of Dyneema ${ }^{\circledR}$ HB 50. Additionally, the first system contained a commonly used soft insert made of 46 layers of Dyneema ${ }^{\circledR}$ SB 21 material, while the other one contained the EA-TP. The Table 1 presents the results of the ballistic resistance of both samples, against the $7.62 \mathrm{~mm}$ x $39 \mathrm{~mm}$ PS bullets, suitable for K 3A class.

The values of average backface signature depth for tested systems fit within the limits of the NIJ Standard-0101.06 (below $40 \mathrm{~mm}$ ) and proves the ballistic resistance against $7.62 \mathrm{~mm}$ × $39 \mathrm{~mm}$ bullets.

Replacing the commonly used soft insert in a ballistic composite system with an EA-TP results in a decreasing of the BSD value by approx. $60 \%$, maintaining the mass of the ballistic composite system. It is clear that in this particular system, shear thickening fluid is more effective in absorbing projectile energy than commonly used soft insert made of 46 layers of Dyneema ${ }^{\circledR}$ SB 21 material. In both compositions first 82 layers of Dyneema ${ }^{\circledR}$ HB 50 are responsible for distribution of the stress over a larger area. Hence more STF and larger area of Dyneema ${ }^{\circledR}$ SB 21 take part in the absorbing process of the projectile energy. What is more, some amount of the projectile energy is used for redistribution of the solid particles inside the STF. Furthermore, rest of the bullet velocity induce growing shear rate inside STF layer, which is responsible for increase of the STF viscosity. Higher viscosity fluids are able to dissipate projectile energy more effectively.
The next step was to verify the stability of the newly developed composite ballistic system during accelerated aging. Figure 6 showed the results of average backface signature depth obtained for samples before and after the aging process.

Ballistic properties of tested samples after 28 days of accelerated aging have shown that deformation value changed only in case of the sample tested after conditioning at the temperature of $-40^{\circ} \mathrm{C}$, where no $\mathrm{BSD}$ has been observed.

For the EA-TP examined after 56 days of accelerated aging, the ballistic properties changed up to $20 \%$ for the samples which were conditioned at the temperature of $+50^{\circ} \mathrm{C}$ or exposed to sprinkling. For the EA-TP examined in the two remaining conditions, the protection properties decreased by $20 \%-35 \%$ when compared to the non-aged sample.

The ballistic properties of the tested EA-TP, after the 84 -day period of aging changed up to $20 \%$, for samples conditioned at the temperature of $+50^{\circ} \mathrm{C}$, and at room temperature. In the cases of samples which were tested after sprinkling or after conditioning at the temperature of $-40^{\circ} \mathrm{C}$, a decrease of the BSD was observed by $26 \%$ and $60 \%$, respectively, in comparison to the EA-TP tested before the aging process.

The highest values of BSD were obtained for samples after conditioning at the temperature of $+50^{\circ} \mathrm{C}$, while the lowest values of BSD were obtained for samples after conditioning at the temperature of $-40^{\circ} \mathrm{C}$.

Moreover it should be noted, that after accelerated ageing, ballistic results for EA-TP are still much better than for composite panel, consisting of 82 layers of Dyneema ${ }^{\circledR}$ HB 50 with soft insert made of 46 layers of Dyneema ${ }^{\circledR}$ SB 21 material. The BSD in the worst case is $31 \%$ lower.

In order to explain differences obtained in the ballistic test results, deep analysis of the elastomeric matrix is presented in the next chapter.

\section{ATR-FTIR spectroscopy}

The aim of the ATR-FTIR analysis was to determine the chemical changes that occurred to the elastomeric materials of the EA-TP during accelerated aging process. The spectra of the EA-TP before and after various exposure times (28, 56 and 84 days) at the elevated temperature are shown in Figure 7.

Stretching vibrations of $\mathrm{Si}-\mathrm{O}-\mathrm{Si}$ which are present in the silicone backbone are responsible for the strongest and broadest peaks which are shown between wavenumbers $1100 \mathrm{~cm}^{-1}$ and $1000 \mathrm{~cm}^{-1}$. The peaks at $\lambda=1258 \mathrm{~cm}^{-1}$ and

Table 1. Ballistic test results for composite systems with soft insert or EA-TP.

\begin{tabular}{|c|l|c|c|c|}
\hline No. & \multicolumn{1}{|c|}{ Ballistic Composite System, CBS } & $\begin{array}{c}\text { Average } \\
\text { Measurement } \\
\text { Velocity, } \\
\mathrm{V}\left[\mathrm{ms}^{-1}\right]\end{array}$ & $\begin{array}{c}\text { Average } \\
\text { Backface Signature } \\
\text { Depth, } \\
\text { BSD [mm] }\end{array}$ & $\begin{array}{c}\text { CBS Mass, } \\
\mathrm{M}^{\mathrm{CBS}}[\mathrm{g}]\end{array}$ \\
\hline 1 & $\begin{array}{l}\text { Soft ballistic insert } \\
\text { behind composite ballistic } \\
\text { panel } \\
\text { (SBS) }\end{array}$ & $725.9 \pm 5.4$ & $30.8 \pm 2.1$ & $\begin{array}{c}\text { Result } \\
\mathrm{P} / \mathrm{S}\end{array}$ \\
\hline 2 & $\begin{array}{l}\text { Elastomeric pad } \\
\text { (EA-TP) behind composite } \\
\text { ballistic panel (EBS) }\end{array}$ & $726.9 \pm 3.1$ & $12.0 \pm 1.8$ & $2123.0 \pm 10.0$ \\
\hline
\end{tabular}

( ${ }^{a} \mathrm{P}$ - perforation of the sample, $\mathrm{S}-$ no perforation of the sample). 


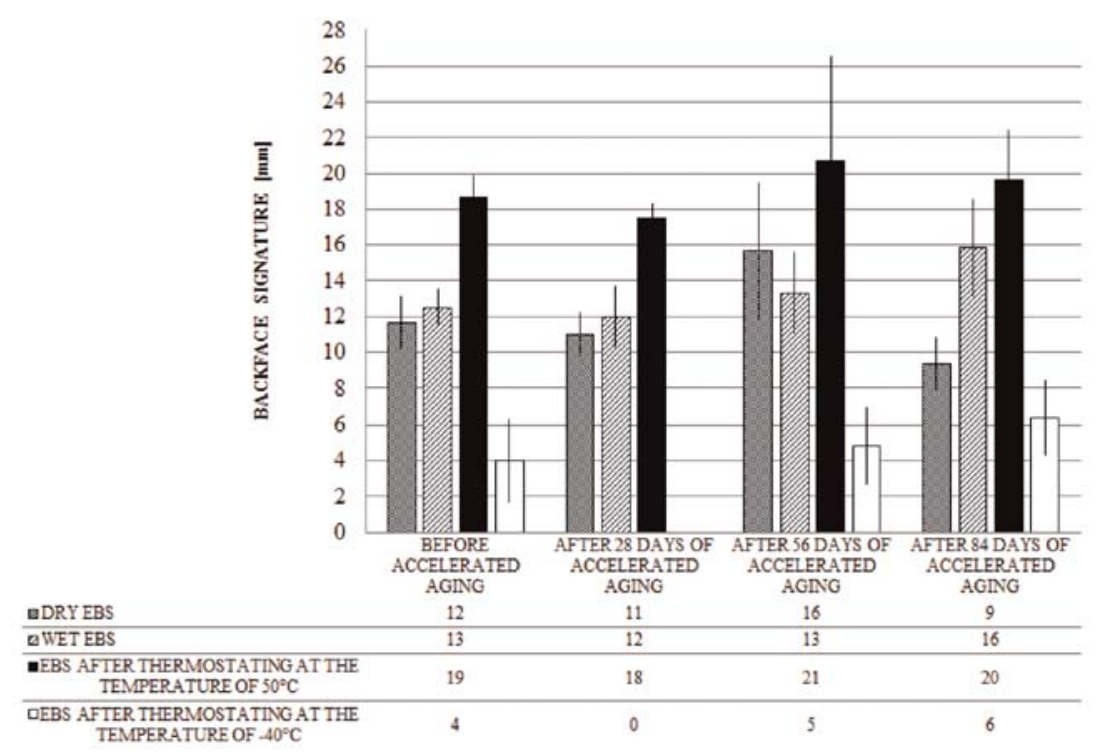

Figure 6. Depth of deformation (backspace signature) for EBS before and after accelerated aging

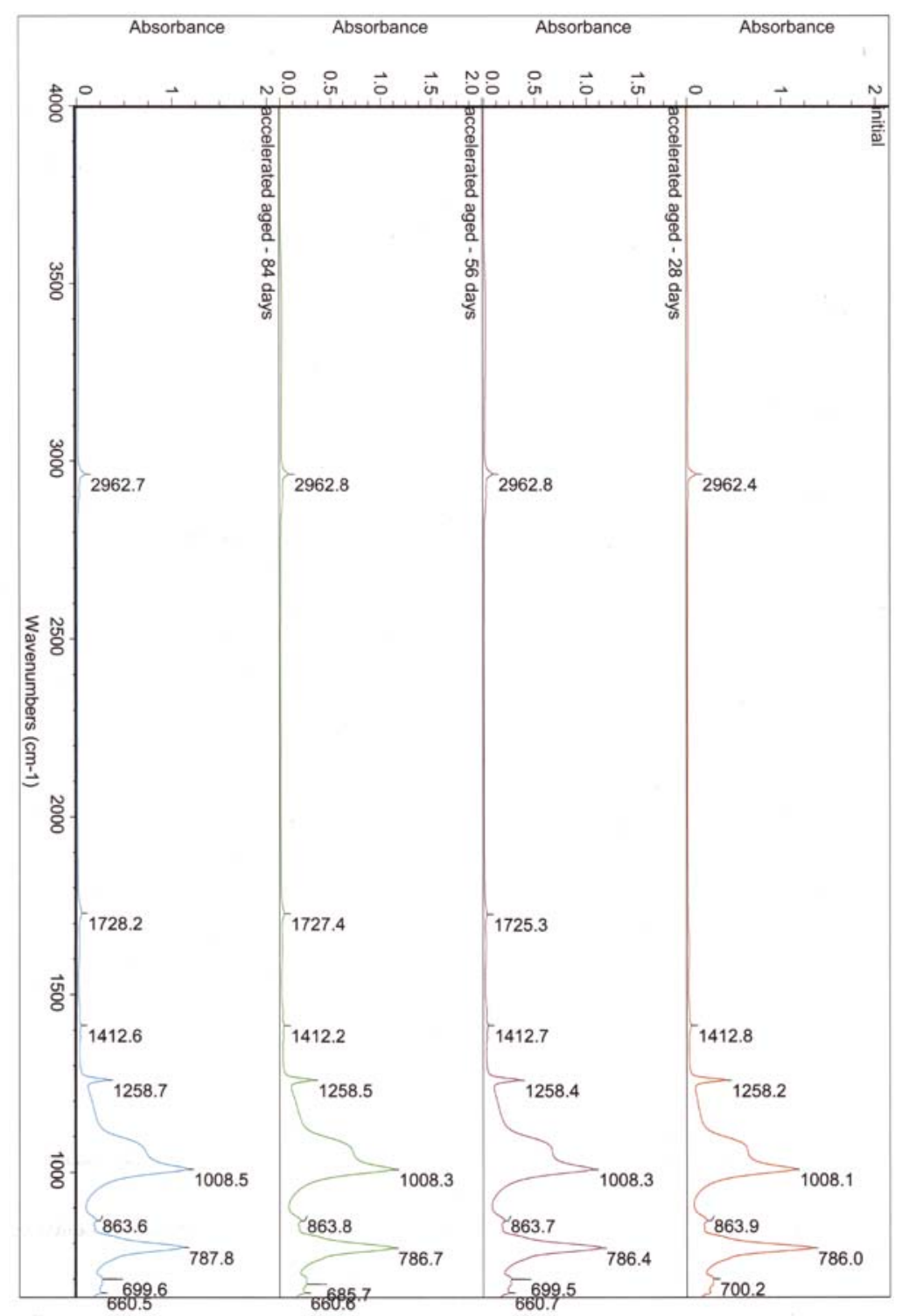

Figure 7. FTIR spectrums of the EA-TP before and after 3 cycles of accelerated aging

$\lambda=786 \mathrm{~cm}^{-1}$ originate from bending vibration of $\mathrm{Si}-\mathrm{CH}_{3}$ and the rocking vibration of $\mathrm{Si}-\mathrm{CH}_{3}$. The peaks at $\lambda=2962$ $\mathrm{cm}^{-1}$ are from the stretching vibration of $\mathrm{CH}_{3}$. The peaks near $\lambda=1412 \mathrm{~cm}^{-1}$ are related to the rocking vibration of $-\mathrm{CH}_{2}-$ as a part of the silicone cross-linked domain.
Moreover, in the spectra of EA-TP after 28, 56 and 84 days of accelerated ageing, a weak absorption band is present at $\lambda=1726 \mathrm{~cm}^{-1}$, which regards to the vibrations of two carbonyl groups. Appearance of this band indicates the oxidation process of the polymer chain, 
which is the result of ageing test ${ }^{15}$. The intensity of this band increases slightly with the progress of the aging process. These changes can be considered as the evidence of thermal resistance of the elastomeric material.

\section{UV-VIS spectroscopy}

The results of the colour measurements of the EA-TP before and after the accelerated aging process are presented in Table 2. The EA-TP after the aging process became brighter, which is indicated by higher values of the $\mathrm{L}^{*}$ coordinates in comparison to the model sample (before the aging process). As the aging process progressed, the values of the $\mathrm{a}^{*}$ colour component were more and more negative, which means that the colour of the examined material shifted towards green. Whereas the $b^{*}$ values became less negative and it has been observed that the colour of the samples became more yellow.

As the aging process progressed, the $\Delta \mathrm{E}$ parameter, which described the colour aberration have increased. The lowest absolute difference of colour, less than 2, was observed for a sample after 28 days of ageing and according to the criterion adopted by the International
Commission of Illumination $\mathrm{CIE}^{\mathbf{1 6}}$, the colour change is unrecognisable. For the sample after 56 days of ageing, the colour index was between 2 and 3.5 which means that there are changes recognisable for an inexperienced observer. EA-TP after 84 days of ageing process was characterised by the biggest value of $\Delta \mathrm{E}$, higher than 7 , which clearly shows a colour deviation of the tested sample compared to the reference (non aged) sample, towards green and yellow. Visible changes, discoloration of the EA-TP, as a result of elevated temperatures impact on a sample indicate a lack of dye's resistance to aging.

\section{Thermographic analysis}

In order to determine the effect of accelerated aging process on the surface and sub-surface changes of the EA-TP, the analysis of temperature distribution on the surface of the samples was performed. Furthermore, the relation of temperature differences of the tested samples as a function of time was executed and shown in Figure 8.

The thermal images acquired during the process of cooling the EA-TP are presented in the table 3. None of the recorded images had thermally changed areas, which

Table 2. Results of the colour measurements of the EA-TP before and after the accelerated aging process.

\begin{tabular}{|l|c|c|c|c|}
\hline \multirow{2}{*}{ Colour coordinate } & \multicolumn{4}{|c|}{ EA-TP } \\
\cline { 2 - 5 } & before aging & after 28 days of aging & after 56 days of aging & after 84 days of aging \\
\hline $\mathrm{L}^{*}$ & 72.33 & 73.27 & 73.69 & 73.03 \\
$\mathrm{a}^{*}$ & -19.46 & -20.24 & -20.27 & -21.40 \\
$\mathrm{~b}^{*}$ & -23.71 & -22.19 & -21.54 & -16.58 \\
$\Delta \mathrm{E}^{\mathrm{a}}$ & - & 1.96 & 2.69 & 7.42 \\
\hline
\end{tabular}

$\left(\mathrm{L}^{*} \mathrm{a}^{*} \mathrm{~b}^{*}-\right.$ system of colour measurement (colour space); $\Delta \mathrm{E}-$ colour index).

Table 3. Thermograms recorded after 3 aging cycles of the EA-TP

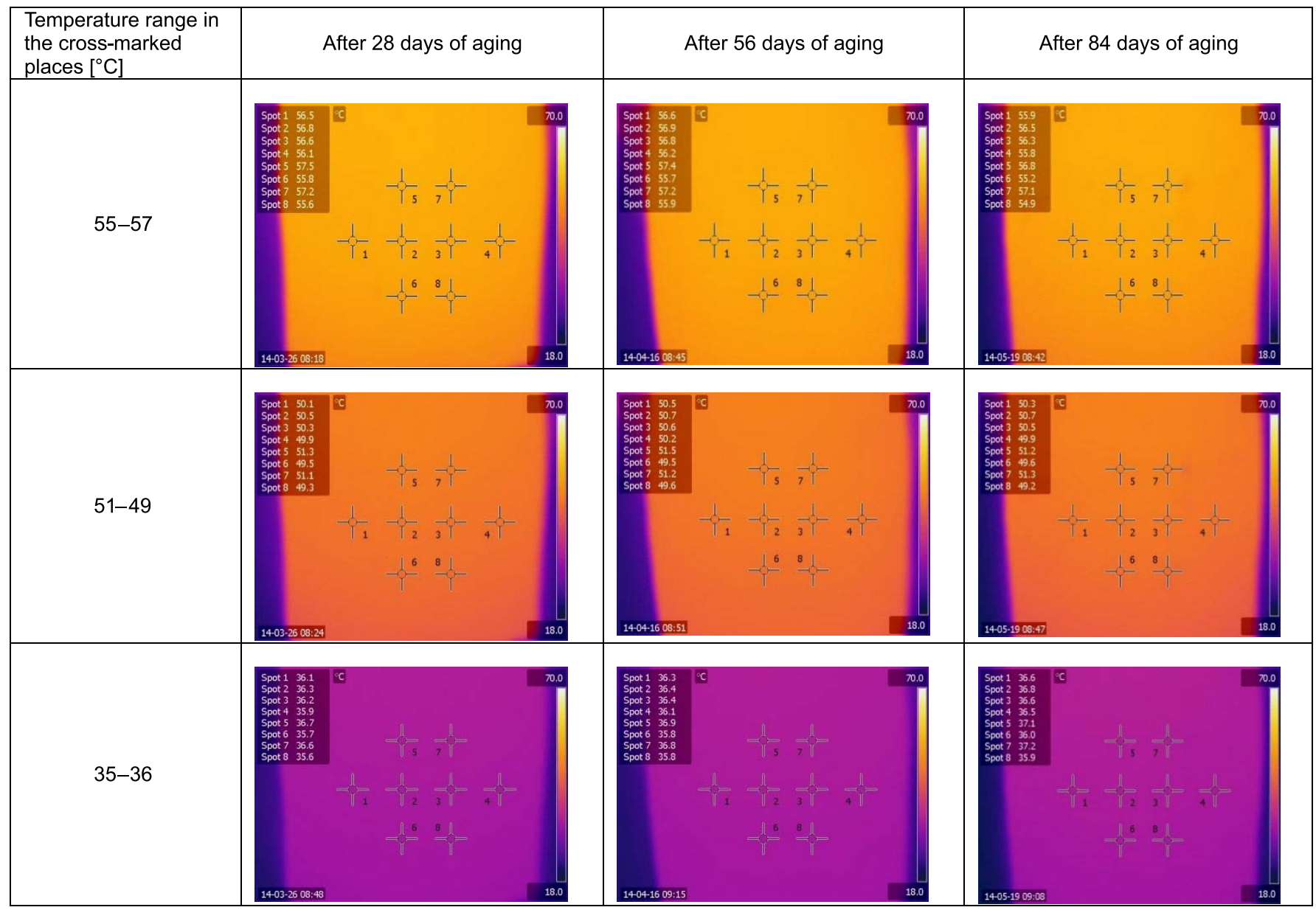




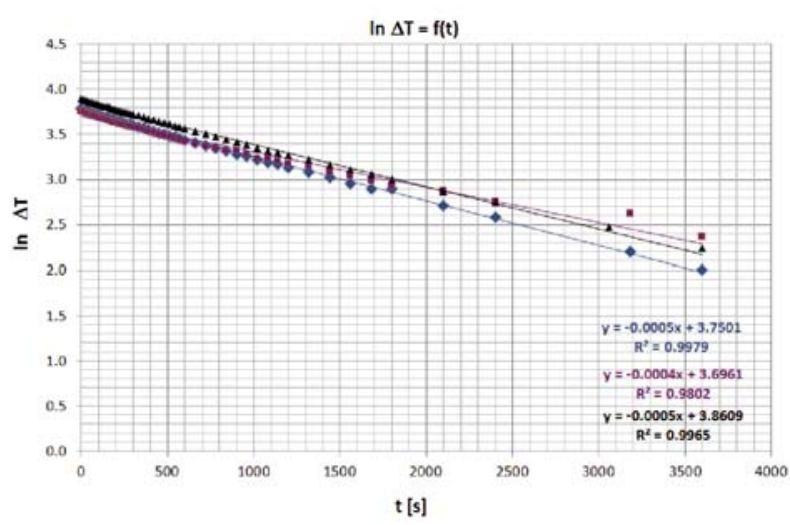

Figure 8. The relation of temperature differences (logarythmised) as a function of time for the EA-TP tested after each of the three ageing cycles, respectively: $\checkmark-28$ days $(\mathrm{k}=0.0005), \mathbf{\square}-56$ days $(\mathrm{k}=0.0004)$, $\Delta-84$ days $(\mathrm{k}=0.0005)$

indicates lack of surface and sub-surface defects caused by the accelerated ageing process. Figure 8 confirms the above observations.

What is more, cooling rate constants of the EA-TP after 28, 56 and 84 days of accelerated ageing are within a very narrow range from 0.0004 to 0.0005 . The slight differences in the cooling rate constants suggest lack or insignificant effect of elevated temperature on the cooling process. Which is additionally confirmed by the lack of surface and sub-surface defects caused by the accelerated ageing process.

From the upper explanation we can see that the elastomeric matrix is resistant to the accelerated ageing process. The lower values of the BSD can be connected with the shear thickening of the fluid. We know that STF components are very sensitive to external conditions which are also responsible for the particles distribution and rheological properties of the STF. Stability of the STF will be subjected in the separable article.

\section{CONCLUSIONS}

The available publications show results for armours with STF but there is no information about their thermal stability over time. The ballistic results gained after accelerated ageing (which simulated the period of 6 years) shown stability over time of the newly-developed elastomeric pad (EA-TP). For the first time such results were shown for the ballistic armours based on STF.

The STF components are vulnerable to external conditions which are affecting the particles distribution and rheological properties. It is clear that sealing STF inside an elastomeric matrix (which revealed not many changes / was resistant to an aging test) is a good way to preserve their ballistic properties over time.

Suspension composed of $25 \%$ volume fraction of 7 $\mathrm{nm}$ fumed silica dispersed in polypropylene glycol with molar mass $400 \mathrm{~g} / \mathrm{mol}$ exhibits shear thickening properties. Moreover, the elastic modulus exceeds viscous modulus in the entire frequency range at constant strain of 5\% which means that the system exhibits properties which are typical rather for solid body than for the liquids.

The newly design $E A$-TP based on STF applied behind the composite ballistic inserts (made of Dyneema ${ }^{\circledR} \mathrm{HB}$ 50 UHMWPE fibrous materials) reduced the average backface signature depth by about $60 \%$ compared to hard ballistic composite with commonly used soft insert. As a result, it would allow for higher energy absorption efficiency of the bullet, thereby decreasing the risk of injury behind the ballistic armour which will be the subject of further studies.

The ATR-FTIR analysis confirmed the presence of a low-intensity band from carbonyl groups in the spectra of elastomeric material after accelerated ageing. This testifies about an inconsiderable impact of the elevated temperature, air (oxygen) on the chemical degradation of the $E A-T P$ surface.

The UV-VIS spectroscopy has allowed to determine the colour index of the EA-TP surface before and after accelerated aging. Obtained values of $\Delta \mathrm{E}$ indicate colour deviation of the aged samples towards green and yellow, as well as lack of dye resistance to accelerated aging process.

Thermographic analysis has shown no visible changes of the $E A-T P$ surface and sub-surface during accelerated aging process. Cooling rate constants proved the lack of changes registered in the thermal images of the surface.

The aforementioned small changes on the surface of $E A-T P$ did not affect the ballistic properties of composite armour. The average BDS values obtained for EA-TP after 28, 56 and 84 days of accelerated ageing proved ballistic resistance to $7.62 \times 39 \mathrm{~mm}$ bullets.

To sum up, the composites armour based on the $E A$ -TP insert maintain ballistic properties after accelerated aging process which was simulating the period of 6 years.

The new combined analysis might be helpful for better understanding of the relationships between natural and accelerated aging process.

\section{ACKNOWLEDGEMENT}

This work has been carried out in a framework of a development project No. UDA-POIG.01.03.01-00-060/08-00, Smart passive body armour with application of rheological and magnetorheological fluids, realized within priority 1 , activity 1.3 , subactivity 1.3.1.

\section{LITERATURE CITED}

1. Light ballistic armours - Ballistic protection vests - Requirements and tests. PN-V-87000:2011.

2. Ballistic Resistance of Body Armor (July 2008). NIJ Standard-0101.06.

3. The $4^{\text {th }}$ International Seminar on Ballistic Protection Genewa 1998 Conference proceedings.

4. Chabba, S., van Es, M., van Klinken, E.J., Jongedijk, M.J., Vanek, D., Gijsman, P., van der Waals, A.C.L.M. (2007). Accelerated aging study of ultrahigh molecular weight polyethylene yarn and unidirectional composites for ballistic applications. J. Mat. Sci. 42, 2891-2893. DOI: 10.1007/s10853-007-1617-7.

5. Ballistic test method for personal armour materials and combat clothing (31 July 2003). NATO STANAG 2920 2nd edition.

6. Meulman, J.H., van der Werf, H., Chabba, S. \& Vunderink, A. (2010). Ballistic performance of Dyneema ${ }^{\circledR}$ at elevated temperatures, extreme for body armor. PASS Conference papers.

7. Padovani, M., Meulman, J.H. \& Louwers, D. (2012). Effect of Real Aging on Ballistic Articles made of Dyneema ${ }^{\circledR}$ UD. PASS Conference papers.

8. Fejdyś, M., Łandwijt, M. \& Struszczyk, M.H. (2011). Effect of Accelerated Aging Conditions on the Degradation Process 
of Dyneema ${ }^{\circledR}$ Polyethylene Composites. Fibres \& Textiles in Eastern Europe 19, 60-65.

9. Light ballistic armours - Ballistic protection vests - Requirements and tests. PN-V-87000:1999.

10. Litwa, P., Kucińska-Król, I., Delczyk-Olejniczak, B. \& Struszczyk, M.H. (2012). Composite inserts for ballistic vests. In. Modern ballistic personal protection and means of the transports made from the fiber composites. Monograph $1^{\text {st }}$ ed. The Institute of Security Technologies "MORATEX" ISBN 978-83-63199-20-3 35-57.

11. Standard Guide for Accelerated Aging of Sterile Barrier Systems for Medical Devices. ASTM F1980 - 07:2002.

12. Rubber - Determination of the resistance to accelerated ageing in the air at the elevated temperature with the measure of tension at a given elongation. PN-88/C-04207.

13. Ballistic tests - determination of the bulletproofness of vests. PBB-17/ITB:2011.

14. Thermographical research. PBB-25/ITB:2012.

15. Kowal, J., Czajkowska, B., Żmihorska-Gotfryd, A., Otfinowski, J., Więcek, A., Wierzbicka, A. \& Wojewoda, J. (2003). Oxidation and degradation of polyethylene cups in hip joint prostheses. Polimery 48, 537-539.

16. Heidelberg, A. (1999). The color and quality. Heidelberg Druckmaschinen, AG Kurfursten-Anlage, 52-60. 